\title{
An Enhanced Web-based Platform for Mobile Learning Management System
}

\author{
A. Alhassan \\ University for Development \\ Studies (UDS) \\ Faculty of Mathematical \\ Sciences (FMS) \\ Department of Computer \\ Science, P.O. Box 24, \\ Navrongo. Ghana.
}

\author{
A. Rashad \\ University for Development \\ Studies (UDS) \\ Faculty of Mathematical \\ Sciences (FMS) \\ Department of Computer \\ Science, P. O. Box 24, \\ Navrongo, Ghana.
}

\author{
K.A. Gbolagade \\ Professor and HOD of \\ Computer, Library and \\ Information Science, Kwara \\ State University, Malete, Ilorin, \\ Kwara State, Nigeria.
}

\begin{abstract}
The research is on the development of an enhanced web-based mobile learning management system which promotes the learner's knowledge, and the entire individual learning system. Though traditional but formal, the classroom has being the adopted way of teaching and learning in most institutions. In this type of learning, students can miss lectures for reasons beyond their control. It is for these reasons that the research and development of a web-based platform for mobile learning is of essence. Making learning mobile and informal can actually provide the required solution. This work presents an enhanced web-based platform solution for mobile learning management system for addressing these problems. The inclusion of an online quiz in the system aids students to know how to properly study the learning materials presented by each specific lecturer and this increases their learning speed and ability. The system therefore is an improvement on the system presented by [1]. The development architecture of the system consists of the Interactive layer, Logic layer, Access layer, and the Storage layer. The Interactive layer is the user interface which is made up of the system user, the mobile devices used to access the internet and also context discovery. The implementation was carried out using Adobe Dreamweaver and Xampp server. The evaluation of the system showed that the practice of mLearning will considerably improve learning system in different facets of learning.
\end{abstract}

\section{General Terms}

Software Development, Improved Learning Practices.

\section{Keywords}

Mobile Learning (m-learning), Structured query Language (SQL), Hypertext markup language (HTML), Adobe Dreamweaver, $\mathrm{PhP}$, management system, web-based.

\section{INTRODUCTION}

In the last few years, the telecommunications industry has experienced an exponential growth in network coverage, speed, and technological innovation around the world. The variety of new products such as smartphones and tablets has enabled students at a distance to choose how they interact with course content and with their lecturers. Until recently, students were only able to access their online course resources through their computers and laptops. Being tied to a desktop or laptop computer restricted their ability to learn and share knowledge while traveling or when in areas without good Internet connectivity [2].

In the mobile learning environment, various mobile devices can be used including mobile phones, PDA, note book computers, Tablet PCs etc. For an effective integration of mobile learning into wireless classroom environment, it is important for all students in a group to have their own computing device equipped with wireless communication capability to conduct learning tasks. Mobile learning reduces the complicated work of the teacher, and allows the teacher to present the readily available materials to the students. Engaging students in learning activities including exploring, organizing online course related resources, answering the questions or assignments using their mobile devices. $\mathrm{mL}$ is the method of e-learning which is based on the use of mobile devices anywhere, any time. It is the integration of data service and mobile service. The teaching and learning process can be implemented anytime, anywhere, on any device cost effectively. The faculty and student could get more detailed information about the subject visually within a reasonable time [4].

In the field of psychology, owning handheld devices increases the student's motivation and deepens the obligation of learning with mobile devices. The present day generation of adults has a fascination on handheld devices like PDA, smart phones and similar devices. These wireless handheld devices have become very popular in almost all countries and it has been used for educational purposes.

Slow learning students can store and revise their lessons any time, any number of times and learn at their own pace. No need to refer to more books for a single topic.

Globally, different definitions have being given per the experiences, uses, and backgrounds. The result of this is a fertile proliferation of views and perspectives. However, the downside is that the unique nature of mobile phone learning is becoming very difficult to characterize. Technologists place a high emphasis on novelty and the functionality of the devices (phones, PDAs, iPods, PSPs) themselves. Some researchers focus on the mobility of the learner. Yet others focus on learning in formal settings, leading to juxtaposition between mobile learning and formal education. 
Furthermore, mobile learning applications are underpinned by many different theories of learning. Whiles this breath of perspective is to be welcomed because it leads to many possibilities for development, it poses problems when trying to develop a theory of mobile learning, the desire to utilize the technologies in the hands of everyone to enhance their learning experiences. Some people suggested that usage of mobile learning technologies in education is the most important of required technologies to provide main goals in distance education. Others were of the view that modern technologies like 3G. Edge and HSDPA facilitates have rapid access to internet and to mobile platforms using high performance packet PCs and PDAs [3]

\section{REVIEW OF LITERATURE}

H. Ryu (2007), worked on the design of a mobile learning experience that aims at assisting university students to organize their learning activities. The development of the system applied a mL design framework to identify appropriate design requirements in practice. Preliminary usability testing on the system revealed the usefulness of the $\mathrm{mL}$ environment for university students. A practical account of this exercise was also described [7].

P. Seppälä (2003), proposed a mobile learning project, where mobile devices are used for educational activities. The main focus was teacher training. Experiences on the use of mobile technology and how it was used in teacher training, especially how trainees and supervising teachers felt about it, was presented. The pilot study was carried out at the Department of Home Economics and Craft Science in University of Helsinki. The idea was that the supervising teacher and trainee students could discus and share their ideas about teaching methods through the mobile device and use of a short message service (SMS) and digital pictures as a part of the supervising process. The use of digital pictures which were delivered via the mobile device proved to be successful. The goal of the pilot project was to create flexible teaching solutions, which will enable access to information using different devices, and support learning in a variety of situations [5].

G. Schwabe (2004), described the design of the Mobile Game prototype, exploring the opportunities to support learning through an orientation game in a university setting. The researcher first introduced the scenario and then described the general architecture of the prototype. The paper focused on the evaluation of design issues and the effects observed in two trials. Design issues include: Supporting work on the move posed difficult interface questions, the accuracy of current outdoor, and indoor positioning systems is still problematic and the game required near real-time response time. The evaluation of the effects showed that features such as 'mapnavigation' and 'hunting and hiding' lead to excitement and fun. The success of the game was based on the motivating design [6].

\section{MATERIALS AND MEETHODS}

The designed architecture of the Enhanced Web-based Platform for Mobile Learning System (EWEBAMOLEMAS) as shown in figure 3, consist of the Interactive layer, Logic layer, Access layer and Storage layer.

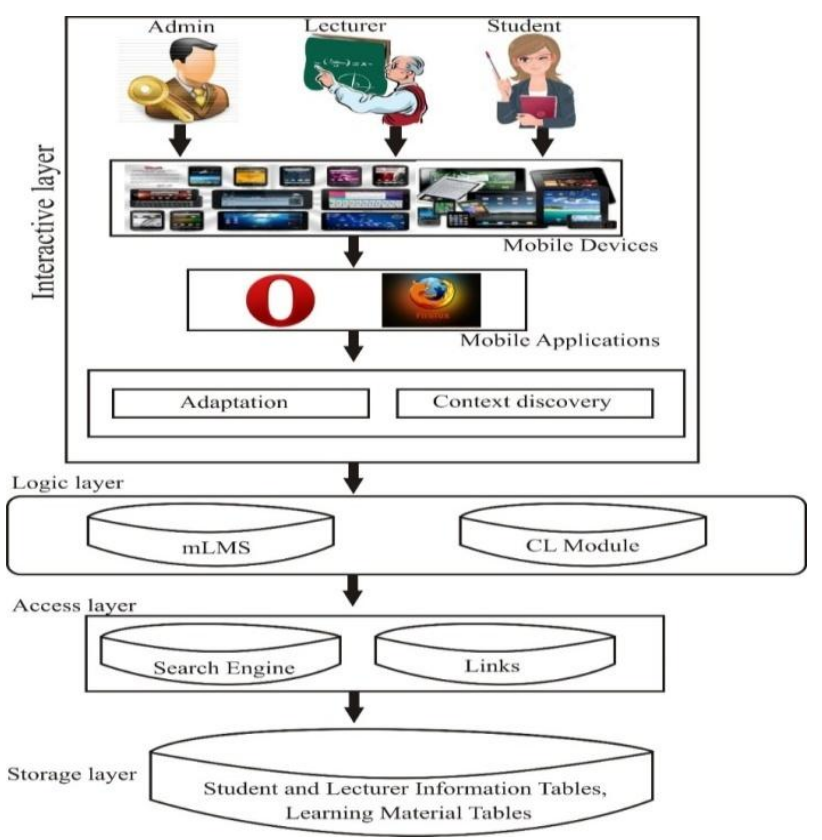

Figure 3: Architecture of an Enhanced Web-Based Mobile Learning Management System

\subsection{Interactive Layer}

The interactive phase is the interface between the user and the system, which directs the user in terms of where to go and what to do depending on the specific kind of user. This phase provides separate interfaces for students, lecturers, and the administrator.

\subsubsection{Users}

Based on the privileges level, the system allows three different kinds of users including the lecturer, student, and administrator.

\subsubsection{Lecturer Portal}

This allows the lecturer to upload learning materials and assignments, and to conduct quizzes and get feedback from the students.

\subsubsection{Student Portal}

This allows students to download learning materials of various courses, and to undertake quizzes, and make inputs to the lecturer.

\subsubsection{Administrator}

This is where the entire system is managed, which includes the management of student and lecturer information, and the maintenance of the system and its resources.

\subsubsection{Mobile Devices}

Devices such as smart phones, tablets and PDA's having mobile applications can be used to visit the enhanced mobile learning management system.

\subsubsection{Mobile Applications}

The client software is mainly client application programs of the mobile equipment operating systems and browsers. Users visit the mobile learning server through the browsers and return the data to the browser according to their requests. 


\subsubsection{Adaptation}

One of the challenges associated with the use of mobile devices for learning is the size of the screen. Content management is therefore carefully considered to make it suitable for different kinds of devices. To facilitate this type of management, the delivery of the learning material is adaptive to better suit the learner and the mobile devices used. Adaptability can be performed in multiple ways and for this purpose various techniques can be used to get all needed data. In the proposed system the profile of the user is retrieved and mobile device specifications are sensed at each new session. The specification of the mobile device is also gathered and accordingly, the contents are displayed on the user's mobile screen. For instance, the size of a picture will be chosen according to the dimension of the mobile device's screen. This will ensure that the information delivered to the learner is properly displayed. The adaptation gathers information about the learner profile and mobile specification which are key elements for content adaptation and delivery [1].

\subsubsection{Context Discovery}

Context discovery refers to identity, spatial information (i.e. location), temporal information and availability of resources (i.e. battery, display, network, and bandwidth etc). The context information could be used not only for specific mlearning services, but also for adapting the services offered by the enhanced mobile learning management system for mobile devices.

\subsection{Logic Layer}

This manages the various services of the system, it receives request from the interactive layer, process it and pass it down to the access layer and further down to the storage layer. The result is sent back to the presentation layer. The two modules in the logic layer that interact within the system are mobile learning management system (mLMS) and course learning (CL) module.

\subsubsection{Mobile Learning Management system (mLMS)}

This is the central point of the enhanced m-learning system for the administration, documentation reporting and delivery of m-learning education courses. The mLMS offers foreground and background services. The foreground comprises services that do not require management, which are mobile application programs like Opera, Mozilla Firefox or the mobile device browsers used to access the internet. The background services are majorly handled by the administrator. The mLMS provides services which include:

1. Handling of both students and lecturers registration information.

2. Handling of all aspects of the learning process including making the system comfortable for mobile learners.

\subsubsection{Course Learning Module (CL)}

Its function is to allow for uploading and downloading of materials by lecturers and students respectively. The student understanding is tested by the taking of the online quiz. It also allows for the deletion of unwanted uploads by the administrator to free the database memory.

\subsection{Access Layer}

The Access Layer is located in the database server and contains the data processing logic in the database server. Its main task is to receive requesting information from the web server, then complete the function of querying, refreshing and changing data in the database. Thereafter, it returns the results to the web server. Data sources (including information tables, learning resource tables, and questions database) for the applications of the m-learning system through the search engine and links are provide by the Access Layer.

\subsection{Storage Layer}

Storage (database) constitutes a core element in the enhanced $\mathrm{m}$-learning system design. The learning system comprises detailed records and tables related to users and learning courses. In addition processed data concerning students learning and instructors are managed in the database. The database management system (DBMS) used is MySQL embedded inside xamp server.

The database design incorporates the tables of records and the relationships among tables. Tables in the enhanced m-learning system can be classified into two categories including learning resource tables and information tables [1]

\section{IMPLEMENTATION AND RESULTS}

The proposed system was implemented on a Dual core 2 Intel microprocessor with Xampp Server 5.6.8 and Adobe Dreamweaver CS6. The program codes were written in PHP and HTML.

The figures below are web pages which indicate how the developed system works.

\subsection{Homepage of the System (EWEBAMOLEMAS)}

This is the interface displayed when the system is installed and run. It contains various command buttons including the SINGUP, CONTACTUS, ABOUTUS buttons etc.

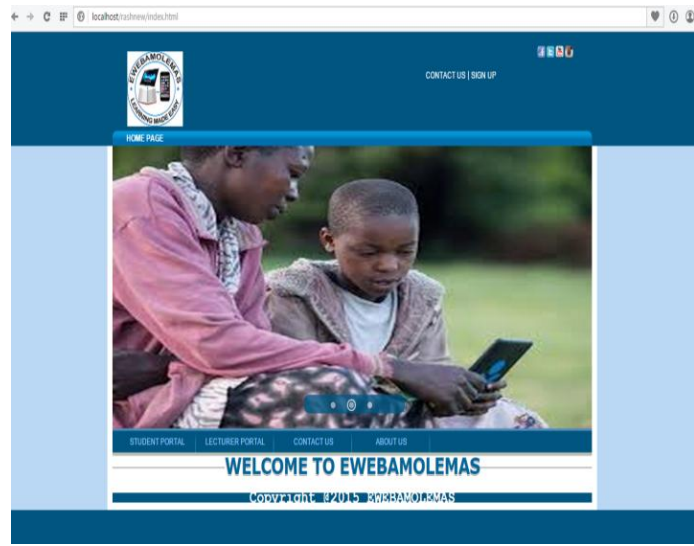

Figure 4 Homepage of EBAMOLEMAS

\subsection{System Login}

The Login interface that give assess to the system depending on the assess level.

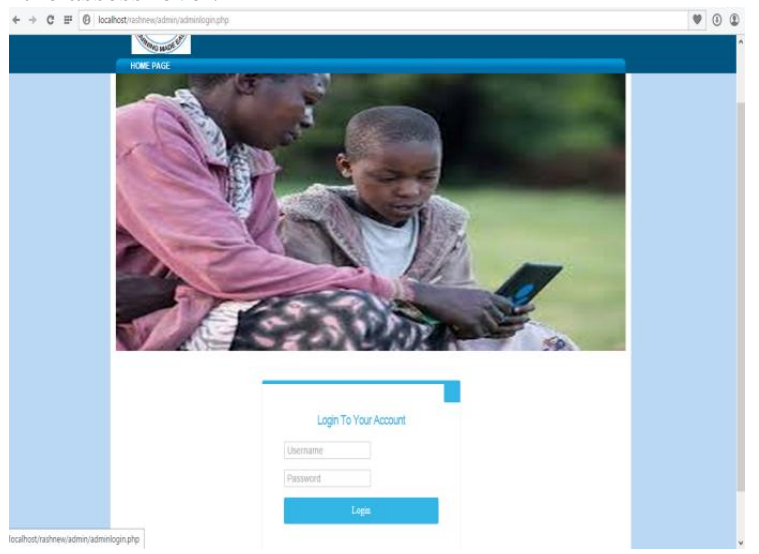

Figure 5 System Login 


\subsection{Lecturer Material Upload Page}

This allows the lecturer to upload quiz and resource material.

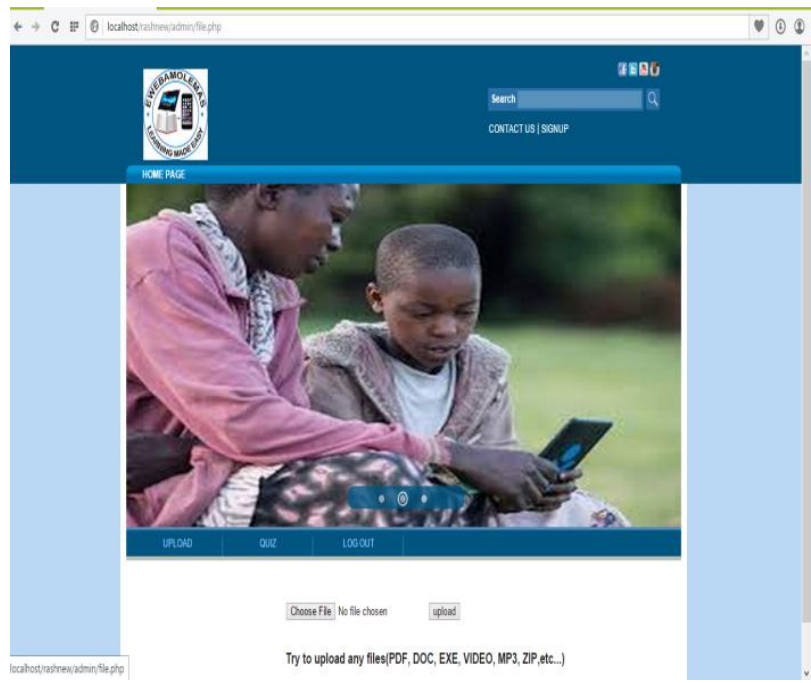

Figure 6 Lecturer Upload Page

\subsection{Learning Material Download Page}

This allows for the student to download course materials

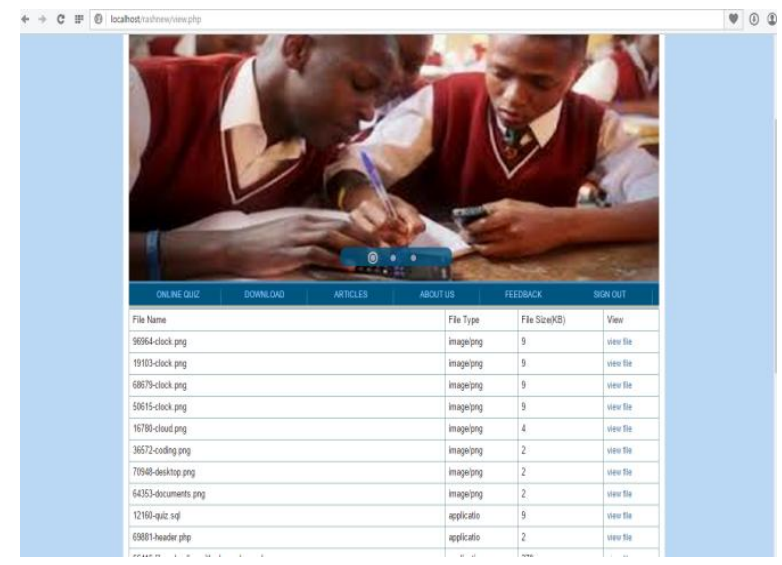

Figure 7 Learning Materials Download Page

\subsection{Online Quiz Page}

This page allows for a student to take an uploaded quiz

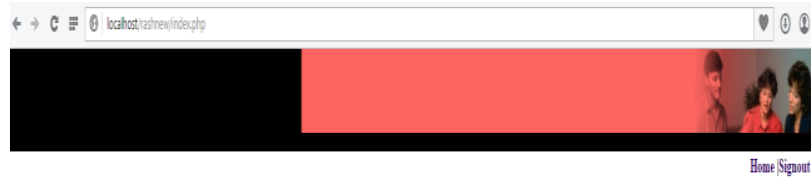

Welcome to 0nline Exam

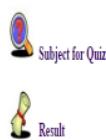

Figure 8 Online Quiz Page

\subsection{Online Quiz Subject Page}

This page shows sample quiz questions undertaken by a student.
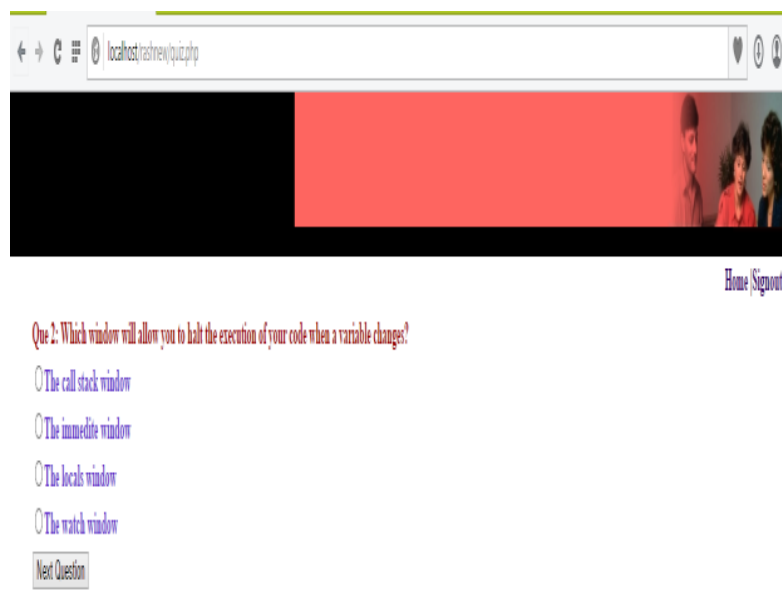

Figure 9 Sample Quiz Questions Page

\section{CONCLUSION}

This project considered an enhanced web-based mobile learning management system (EWEBAMOLEMAS) whose architecture consists of four main layers namely; Interactive layer, Logic layer, Access layer and Storage layer. The implementation was carried out using Adobe Dreamweaver and Xampp server. Mobile phones, PDA, notebook computers can be used to download the learning materials using the wireless network technology. Php codes to aid the adaptation of the system to these mobile devices have been included behind every webpage. The student, with access to a network using mobile devices can connect to learn from teachers and lecturers. The educational process will become more flexible therefore to the needs of lifelong learning. The system can also be a good educational tool for disabled people. The existence of the online quiz within the system aids the learner to know how to study the learning materials provided by various lecturers and also send feedback on the materials and quizzes. The system therefore is an improvement on the system developed by A.J Ikuomola and O.N Nureini (2013). The evaluation of the system showed that the practice of $\mathrm{mL}$ will actually improve learning system in different aspects of learning.

\subsection{Future Work}

In the future, the system can be extended to include direct online tutorials between a Lecturer and a student which can further increase student's understanding and clarification in the education process.

\section{REFERENCES}

[1] Ikuomola A.J and Nureini O.N (2013), A web based platform for mobile learning, of Ondo State University of science and technology and Federal university of Agriculture Abeokuta respectively, The journal of computer science and its applications, page 49-51.

[2] Dutta S. (2012), The Global Information Technology Report, World Economic Forum Editors. Pg 14.

[3] Hemabala J.and Suresh M. (2012), The Frame Work Design of Mobile Learning Management System, of Educational Media Centre and Department of Civil Engineering respectively, of NITTTR Taramani 
Chennai-113, International Journal of Computer and Information Technology, pp 179-183.

[4] Dochev D. and Hristov I. Institute of Information Technologies, 1113 Sofia, Cybernetics and Information Technologies Volume 6, No 3.

[5] Seppälä P. and Alamäki H. (2003), "Mobile learning in teacher training". Journal of Computer Assisted Learning no. 19.

[6] Schwabe G. and Göth C. (2004), "Mobile Learning with a Mobile Game: Design and Motivational Effects," Journal of Computer Assisted Learning, vol. 21.

[7] Ryu H. Brown R, (2007), "Personal Learning Organiser: Designing a Mobile learning experience for university students", presented at the Conference on Mobile Learning Technologies and Applications (MoLTA), Auckland, New Zealand.

[8] Singhd D. and Bakar Z. A. (2006), Mobile Learning in Wireless Classrooms, Malaysia Online Journal of Instructional Technology (MOJIT) Vol 3. pp. 26-42.

[9] Parsons D., A study of Design Requirements for Mobile Learning Environments, Massey University, Auckland, New Zealand.

[10] Sitthiworachart J.,"Is Mobile Learning a Substitute for Electronic Learning?" Faculty of Information Technology King Mongkut's University of Technology North Bangkok, Thailand.

[11] Bhaskar N. U., Aspects of Content, Context and Adaptation Modelling In Mobile Learning Application Design, Govt. Degree College, Pattikonda, A.P., India.
[12] Douglas B. (2005), Software Engineering for Students A Programming Approach, pp 23, 37, 317, 318.

[13] Brown I. (2009), Art on the move: Mobility - a way of life, University of Wollongong.

[14] Al-Busaidi A. and Al-Shihi H. (2010), Instructors' Acceptance of Learning Management Systems: A Theoretical Framework, IBIMA Publishing Vol. 2010.

[15] Andronico A., Integrating a multi-agent recommendation system into a Mobile Learning Management System, Dipartimento di Ingegneria Dell'informazione.

[16] Skouradaki M. (2013), Enhancing Learning Management Systems (LMS) with the use of Web Technologies, Computer Science Department University of Crete, 7th International Conference in Open \& Distance Learning.

[17] Lwoga E., Critical success factors for adoption of webbased learning management systems in Tanzania, Muhimbili University of Health and Allied Sciences, Tanzania, International Journal of Education and Development using Information and Communication Technology (IJEDICT), 2014, Vol. 10, Issue 1.

[18] Colazzo L. (2003), Towards a multi-vendor Mobile Learning Management System, Department of Computer and Management Sciences, University of Trento, presented at the World Conference on ELearning.

[19] En.wikipedia.org. (internet reference)

[20] Woodard R. (2011), Advantages and Disadvantages of m-Learning 